\title{
ОБЩИЕ ТЕНДЕНЦИИ РАЗВИТИЯ СИСТЕМЫ РЕГУЛИРОВАНИЯ ИНТЕЛЛЕКТУАЛЬНЫХ ПРАВ НА ПРИМЕРЕ ЗАКОНОДАТЕЛЬСТВА ЕВРОПЕЙСКОГО СОЮЗА
}

Аннотация. Предметом исследования настоящей статьи является анализ развития законодательства Европейского Союза в сфере интеллектуальной собственности как отражение общих тенденций трансформациии правового регулирования интеллектуальных прав в изифровую эпоху. Особое внимание уделяется особенностям инновационной экономики. Автором отмечается, что происходит усиление защиты интересов правообладателей. В то же время интерактивный характер изифровой экономики и распространение новых способов получения знания ставят перед правом интеллектуальной собственности задачу обеспечения свободного доступа к контенту. В статье автором был использован сравнительно-правовой метод с учетом диспозитивного и императивного методов международного права. Сделан вывод, что своеобразие права ЕС состоит в том, что оно объединяет в себе характеристики международного права и самостоятельной правовой системы. Описанные в статье устойчивые тенденции в развитии европейского права свидетельствуют о формировании предпосылок для смены парадигмы регулирования интеллектуальных прав.

Ключевые слова: Интеллектуальные права, интеллектуальная собственность, законодательство Европейского союза, рыночная экономика, инновационная экономика, информациионные технологии, человеческий капитал, доступ кинформации, правовая парадигма, гибкое регулирование.

Abstract: The subject of this research is the analysis of development of the EU legislation in the area of intellectual property as a reflection of general trends of transformation of the legal regulation of intellectual rights into the digital age. A special attention is given to the aspects of innovational economy. The author notes that there is a strengthening of the protection of the right holders' interests. At the same time the interactive nature of the digital economy and the spread of new ways of acquiring knowledge present the law of intellectual property with a task of providing a free access to content. The author concludes that the uniqueness of the EU legislation consists in the fact that it combines the characteristics of international law and independent legal system. The described consistent trends of development of the European law show the forming of prerequisites for a change in the paradigm of regulation of intellectual rights.

Keywords: Intellectual rights, intellectual property, EU legislation, market economy, innovation economy, information technologies, human capital, access to information, legal paradigm, flexible regulations.

вропейское законодательство в сфере защиты интеллектуальных прав за последнее десятилетие претерпело значительные изменения. Изменения, прежде всего, связаны с процессами унификации и гармонизации права Европейского Союза в сфере интел- лектуальной собственности. Доктор юридических наук, профессор А.И. Абдуллин связывает данные процессы с «императивами рыночной экономики» и указывает на их своеобразие, которое заключается в их двунаправленности: повышение уровня правовой охраны результатов соседствует 
с ограничением правомочий правообладателей $[1$, с.9-11]. Действительно, информационные технологии и наукоемкие производства становятся основными драйверами современной экономики, а интеграция правового регулирования, как справедливо отмечает Е.И. Игнатущенко, является важным «катализатором» роста количества научных знаний и увеличения объема международной торговли [2]. Вместе с переходом от индустриальной эпохе к обществу и экономике знания существенно возросло значение человеческого капитала как источника интеллектуального творчества и основы инновационного производства. Как отмечает С.Г. Михнева, «знания и творческий потенциал работников становятся главным фактором эффективности экономической системы» $[3$, с.50, 4].

Таким образом, общий вектор развития законодательства в сфере регулирования интеллектуальных прав предполагает совмещение интересов бизнеса и интересов общества, которые касаются образования, науки и культуры. Задача обеспечения эффективной защиты исключительных прав на результаты интеллектуальной деятельности в условиях информационного общества сочетается с задачами развития модели открытых инноваций и обеспечения свободного доступа к знаниям и культуре как необходимому условию формирования профессиональных кадров, отвечающих новым потребностям экономики. Иными словами, хотя конечной целью права интеллектуальной собственности является конкурентоспособная экономика, в выигрыше могут и должны оказаться социально ориентированные сферы. Указанные тенденции в полной мере находят свое отражение в законодательных инициативах Европейского союза

Так, в 2005 году стартовал проект «і2010: цифровые библиотеки» [5], а в
2006 году Европейская комиссия опубликовала Рекомендации по цифровизации и он-лайн доступности и цифровому сохранению материалов в сфере культуры [6]. С момента принятия Рекомендаций цифровизация объектов культуры существенно увеличилась.

В 2010 году была запущена Программа действий в области цифровых технологий для Европы (Digital Agenda for Europe) [9]. Комиссар Европейского союза, отвечающий за данную программу, Ниили Кроес (Neelie Kroes) выразила значение цифровой экономики в следующих емких словах: «Европейская цифровая экономика - ключевой фактор для экономического роста и процветания. ИКТ и высокоскоростной интернет являются для нашей сегодняшней жизни столь же революционными как развитие электричества и транспортных сетей столетие назад» [13]. Развитие информационно-коммуникационных технологий не является, однако, самостоятельной целью Программы действий. Важнее то, что информационные технологии рассматриваются как одно из ключевых направлений для экономического роста Европы, ее выхода из кризиса и как основа для успешной конкуренции с США [15].

Уже упомянутый проект «і2010: цифровые библиотеки» с 2010 года является частью Программа действий в области цифровых технологий для Европы. И, знаменательно, насколько интенсивно с этого момента стала продвигаться реализация проекта. Особенно показательным является 2011 год.

В январе 2011 года был опубликован доклад Комитета мудрецов (Comite des Sages) Европейской Комиссии под емким название «Новое Возрождение»и посвященный вопросу перенесения европейского культурного наследия в Интернет [18].

В мае 2011 года Европейская Комиссия выпустила Послание «Единый рынок 
прав интеллектуальной собственности, поддерживающий творчество и инновации для обеспечения экономического роста, качественной работы и первоклассных продуктов и услуг в Европе» [11]. Технологический прогресс изменил способы ведения бизнеса, а также распространения и потребления продуктов и услуг и, как следует из послания, европейское законодательство должно стимулировать инвестиции и инновации в условиях добросовестной конкуренции и облегчения распространения знаний [11, c.4]. Основная задача заключается в том, чтобы сделать Европу «мировым лидером по инновационным лицензионным решениям для беспрепятственного использования инновационных технологических продуктов, а также знания и продуктов культуры» $[11$, с.6].

Новое «прочтение» получили также интересы и взаимоотношения различных субъектов рынка. Тремя основными «игроками», взаимоотношения между которыми должно оптимизировать новое рамочное регулирование исключительных прав, признаются авторы, провайдеры услуг и контента, и пользователи. В качестве цели было намечено также достижение «необходимого баланса между защитой прав и доступом», когда выплата вознаграждения и иное стимулирование авторов и изобретателей сочетается с беспрепятственным распространения товаров и услуг, осуществлением фундаментальных прав, поощрением и сохранением культурного и языкового разнообразия.

Наряду с задачей достижения баланса, Европа планирует дальнейшее усиление инструментов по принуждению к соблюдению интеллектуальных прав, причем как на уровне Европейского Союза, так и на международном уровне. Для достижения данной цели будут приняты поправки в Директиву 2004/48 Европейского пар- ламента и Совета ЕС от 29 апреля 2004 г. об обеспечении прав на интеллектуальную собственность. Особого внимания, однако, заслуживает, что параллельно с поправками в Директиву Европейская Комиссия рассматривает как актуальную задачу анализ перспектив использования добровольных мер (voluntary measures) по защите интеллектуальных прав . Примером таких мер является принятие 4 мая 2011 года в Брюсселе Меморандума о взаимопонимании между правообладателями и сервис-провайдерами, целью которого является борьба с продажей контрафактной продукции через Интернет [17].

Планируемая реформа патентного права предусматривает значительное упрощение и удешевление процедуры патентования, позволяющее сделать патентную защиту доступной даже для самых мелких компаний. С другой стороны, необходимым условием увеличения доходов авторов Европейская Комиссия считает облегчение лицензирования и распространения произведений на едином цифровом рынке $[11$, с.9]. В противоположность прошлым инициативам, которые ставили во главу угла защиту правообладателей, теперь целью является реализация потенциала возможностей, которые приносят с собой информационные технологии. Иначе воспринимается теперь и лицензирование - его задача состоит не в обеспечении правообладателю справедливого вознаграждения, чему, видимо, отводится отныне второе место, а в обеспечении для миллионов граждан возможности легко и на законной основе использовать знания и развлекательную продукцию, а также делиться ими на всей территории Союза, независимо места жительства $[11$, с.10]. Не был забыт в Послании также и контент, создаваемый самими пользователями (так называемый «user-generated content»). По данному вопросу планируется сделать 
легким и доступным использование в любительском контенте произведений, права на которые принадлежат третьим лицам.

В октябре 2011 Европейская Комиссия опубликовала свои Рекомендации по вопросу оцифровки и сохранения материалов в сфере культуры [7]. Для оцифровки материалов, находящихся под защитой авторского права, Комиссия рекомендовала, в частности, скорейшую имплементацию Директивы о сиротских произведениях, а также создание правовых условий для широкомасштабного лицензирования произведений, которые не пользуются коммерческим спросом. В отдельный параграф рекомендаций была выделена общеевропейская он-лайн библиотека Europeana. Так, одним из способов содействия наполнению ее фондов должно стать государственное финансирование различных проектов по оцифровке произведений под условием их последующей доступности также и в библиотеке Europeana. Уже в следующем году, в октябре 2012 года была принята Директива 2012/28/EU об определенных случаях разрешенного использования сиротских произведений. Сиротское произведение или фонограмма признается таковым, если ни один обладатель прав на такое произведение или фонограмму не установлен или, если один или несколько из них установлены, ни один не может быть обнаружен, несмотря на проведение должного поиска правообладателя. Директива устанавливает общий подход к идентификации авторов сиротских произведений и общие правила, касающиеся использования таких произведений общедоступными библиотеками, образовательными учреждениями и музеями, архивами и организациями общественного вещания. Такая гармонизация в регулировании необходима, прежде всего, в целях обеспечения правовой определенности на внутреннем рынке Европейского союза.
В 2012 году Европейская комиссия опубликовала рекомендации по вопросу о доступе к научной информации и ее сохранении [8]. Впервые на общеевропейском уровне данная проблема рассматривалась Советом Европейского союза в 2007 году. В 2008 году Европейской комиссией был запущен Пилотный проект по открытому доступу (Open Access Pilot Project). Его цель - обеспечить свободный и бесплатный он-лайн доступ ученых и любых других заинтересованных лиц к результатам научных исследований, которые финансируются на уровне ЕС. Прежде всего, речь идет о научных статьях. На рамочную программу исследований, которая рассчитана на период с 2007 по 2013 год, выделено 50 миллиардов евро. В общеевропейских рекомендациях 2012 года указывается, что открытый доступ к публикациям должен стать общзим принциипом для всех исследований, которые финансируются европейскими государствами. На настоящем этапе поставлена более масштабная задача - обеспечить открытый доступ к исследованиям, финансируемым из разных источников, а также создать условия для систематизации и сохранения научной информации, объем которой постоянно растет. Открытый доступ должен предоставляться в максимально краткие сроки после публикации, предпочтительно сразу же, но не позднее шести месяцев после даты публикации для естественных наук и двенадцати месяцев для гуманитарных наук.

В июле 2011 года Европейская Комиссия выпустила Зеленую книгу «Об он-лайн распространении аудиовизуальных произведений на территории Европейского Союза: возможности и вызовы для единого цифрового рынка» [16]. Знаменательно, что по данному вопросу, как и по всем до этого перечисленным, «героем дня» выступает не правообладатель, теряющий свои дохо- 
ды из-за деятельности пиратов, а пользователь, желание которого «смотреть все что угодно, где угодно, в любое время и на любом оборудовании» становится направляющим вектором для постановки задач и поиска их решений. Стратегия, направленная на обеспечение открытого доступа к информации, которая охраняется правом интеллектуальной собственности, получила свое дальнейшее развитие в Послании Европейской комиссии «О контенте на Едином цифровом рынке» [10].

Представленный обзор тенденций развития законодательства по интеллектуальной собственности Европейского союза позволяет сделать общий вывод о формировании необходимых предпосылок для смены правовой парадигмы.

Bo-nepвblx, изменяет общий подход к пониманию задач, которые стоят перед регулированием интеллектуальных прав. Речь уже не идет о том, как бороться правовыми и техническими средствами с неизбежным «злом»информационных технологий - доступным копированием. На повестку дня выходит вопрос о необходимой адаптации правового режима интеллектуальной собственности к требованиям информационной экономики и новым общественным отношениям. Bo-вmopblx, подвергается переосмыслению роль пользователя как субъекта правоотношений в сфере интеллектуальной собственности. Получает признание право потребителя использовать авторские произведения для создания своих собственных любительских произведений. B-mpemьих, обеспечение свободного доступа к контенту становится уже не столько вопросом социальной функции интеллектуальных прав, которая выступает как исключение по отношению к коммерческому использованию результатов интеллектуальной деятельности, сколько комплексной задачей обеспечения соответствия регулирования инновационной экономике с eе новыми бизнес моделями и центральной ролью человеческого капитала. Наконец, в-четвертыx, дифференциация способов правового регулирования, которые использует Европейский союз (директивы, рекомендации, заключения, судебное правотворчество, саморегулирование) свидетельствует об осознании принципиальных недостатков действующего законодательства и попытке сгладить существующие противоречия посредством максимальной гибкости регулирования.

\section{Библиография:}

1. Абдуллин А. И. Право интеллектуальной собственности в Европейском Союзе: Генезис, унификация, перспективы развития. Автореферат диссертации на соискание ученой степени доктора юридических наук. Специальность 12.00.03. - Гражданское право ; Предпринимательское право ; Семейное право ; Международное частное право. Специальность 12.00.10-Международное право ; Европейское право. Москва, 2006. $-63 \mathrm{c}$.

2. Игнатущенко Е.И. Интеллектуальная собственность - как основа создания рынка наукоемкой продукции в России и ЕС. // Мировое и национальное хозяйство №3(22), 2012. [Электронный pecypc]. Режим доступа: URL: http://www.mirec.ru/index.php?option=com_content\&task=view\&id=29.html Дата обращения: 25.12.2014.

3. Михнева С.Г. Интеллектуализация экономики: инновационное производство и человеческий капитал / С.Г. Михнева // Инновации. - 2003. № 1 (58). - С.49-60.

4. Трошин А.В. Человеческий капитал как фактор развития инновационной экономики России // Современная экономика: проблемы и решения. № 9 (9). - M., 2010. - С.49-52. 
5. Communication from the Commission to the European Parliament, the Council, the European Economic and Social Committee and the Committee of Regions "i2010: Digital Libraries" Brussels 30.9.05 COM (2005) 465 final.

6. Commission Recommendation 2006/585/EC of 24 August 2006 on the digitisation and online accessibility of cultural material and digital preservation. Official Journal of the European Union, L 236/28.

7. Commission Recommendation on the digitisation and online accessibility of cultural material and digital preservation. Brussels, 27.10.2011. C(2011) 7579 final.

8. Commission Recommendation on access to and preservation of scientific information. Brussels, 17.7.2012. C(2012) 4890 final.

9. Communication from the Commission to the European Parliament, the Council, the European Economic and Social Committee and the Committee of the Regions A Digital Agenda for Europe. COM (2010) 0245.

10. Communication from the Commission on content in the Digital Single Market. Brussels, 18.12.2012. COM(2012) 789 final.

11. Communication from the Commission to the European Parliament, the Council, the European Economic and Social Committee and the Committee of the Regions on a Single Market for Intellectual Property Rights Boosting creativity and innovation to provide economic growth, high quality jobs and first class products and services in Europe. Brussels, 24.5.2011. $\operatorname{COM}(2011) 287$ final.

12. Council Conclusions on scientific information in the digital age: access, dissemination and preservation. 2832nd Competitiveness (Internal market, Industry and Research) Council meeting Brussels, 22 and 23 November 2007.

13. Digital Agenda: investment in digital economy holds key to Europe's future prosperity, says Commission report. Press Release. № IP/10/571. Brussels, 17 May 2010.

14. Directive 2004/48/EC of the European Parliament and of the Council of 29 April 2004 on the enforcement of intellectual property rights.

15. Europe's Digital Competitiveness Report. Brussels, 17.5.2010, SEC (2010) 627.

16. Green Paper on the online distribution of audiovisual works in the European Union: opportunities and challenges towards a digital single market. Brussels, 13.7.2011 COM(2011) 427 final.

17. Memorandum of Understanding on the sale of Counterfeit Goods over the Internet. [Электронный ресурс]. Режим доступа: URL: http://ec.europa.eu/internal_market/iprenforcement/docs/memorandum_04052011_en.pdf Дата обращения: 25.12.2014.

18. The New Renaissance, Report of the 'Comité des Sages' Reflection group on bringing Europe's Cultural Heritage online. Brussels, 2011.

\section{References (transliterated):}

1. Abdullin A. I. Pravo intellektual'noi sobstvennosti v Evropeiskom Soyuze: Genezis, unifikatsiya, perspektivy razvitiya. Avtoreferat dissertatsii na soiskanie uchenoi stepeni doktora yuridicheskikh nauk. Spetsial'nost' 12.00.03. - Grazhdanskoe pravo; Predprinimatel'skoe pravo; Semeinoe pravo; Mezhdunarodnoe chastnoe pravo. Spetsial'nost' 12.00.10-Mezhdunarodnoe pravo; Evropeiskoe pravo. Moskva, 2006. - 63 s.

2. Ignatushchenko E.I. Intellektual'naya sobstvennost' - kak osnova sozdaniya rynka naukoemkoi produktsii v Rossii i ES. // Mirovoe i natsional’noe khozyaistvo №3(22), 2012. [Elektronnyi resurs]. Rezhim dostupa: URL: http://www.mirec.ru/index.php?option=com _ content\&task=view\&id=29.html Data obrashcheniya: 25.12.2014. 
DOI: $10.7256 / 2226-6305.2015 .1 .14148$

При цитировании этой статьи сноска на dоі обязательна

Интеграционное право и наднациональные объединения / Integration law and subpranational unions

3. Mikhneva S.G. Intellektualizatsiya ekonomiki: innovatsionnoe proizvodstvo i chelovecheskii kapital / S.G. Mikhneva // Innovatsii. - 2003. № 1 (58). - S. 49-60.

4. Troshin A.V. Chelovecheskii kapital kak faktor razvitiya innovatsionnoi ekonomiki Rossii // Sovremennaya ekonomika: problemy i resheniya. № 9 (9). - M., 2010. - S. 49-52. 